\title{
Postgraduate Interprofessional Case-Based Learning in Childhood Cancer: A Feasibility Study
}

\author{
Martha Krogh Topperzer ${ }^{1, *(1)}$, Marianne Hoffmann ${ }^{2}$, Hanne Bækgaard Larsen ${ }^{1,3}$, Susanne Rosthøj ${ }^{4}$, \\ Martin Kaj Fridh ${ }^{1}\left(\mathbb{D}\right.$, Louise Ingerslev Roug ${ }^{1}$, Liv Andres-Jensen ${ }^{1}$, Peter Erik Lokto Pontoppidan ${ }^{2}$, \\ Kjeld Schmiegelow ${ }^{1,3,5}$ (1) and Jette Led Sørensen ${ }^{3,4,5}$
}

1 Paediatric Oncology Research Laboratory, Department of Paediatrics and Adolescent Medicine, Copenhagen University Hospital-Rigshospitalet, 2100 Copenhagen, Denmark; hanne.baekgaard.larsen@regionh.dk (H.B.L.); martin.kaj.fridh@regionh.dk (M.K.F.); louise.ingerslev.roug@regionh.dk (L.I.R.); liv.andres-jensen.02@regionh.dk (L.A.-J.); Kjeld.Schmiegelow@regionh.dk (K.S.)

2 Department of Paediatrics and Adolescent Medicine, Copenhagen University Hospital—Rigshospitalet, 2100 Copenhagen, Denmark; marianne.hoffmann@regionh.dk (M.H.); peter.erik.lotko.pontoppidan@regionh.dk (P.E.L.P.)

3 Department of Clinical Medicine, Copenhagen University Hospital—Rigshospitalet, 2100 Copenhagen, Denmark; Jette.led.soerensen@regionh.dk

4 Section of Biostatistics, Faculty of Health Sciences, Copenhagen University Hospital—Rigshospitalet, 2100 Copenhagen, Denmark; sro@sund.ku.dk

5 Juliane Marie Centre, Copenhagen University Hospital—Rigshospitalet, 2100 Copenhagen, Denmark

check for updates

Citation: Topperzer, M.K.; Hoffmann, M.; Larsen, H.B.; Rosthøj, S.; Fridh, M.K.; Roug, L.I.; Andres-Jensen, L.; Pontoppidan, P.E.L.; Schmiegelow, K.; Sørensen, J.L. Postgraduate Interprofessional Case-Based Learning in Childhood Cancer: A Feasibility Study. Cancers 2021, 13, 4314. https://doi.org/ 10.3390/cancers13174314

Academic Editor: David Wong

Received: 21 May 2021

Accepted: 24 August 2021

Published: 26 August 2021

Publisher's Note: MDPI stays neutral with regard to jurisdictional claims in published maps and institutional affiliations.

Copyright: (c) 2021 by the authors. Licensee MDPI, Basel, Switzerland. This article is an open access article distributed under the terms and conditions of the Creative Commons Attribution (CC BY) license (https:// creativecommons.org/licenses/by/ $4.0 /)$.
Simple Summary: In childhood cancer healthcare, interprofessional education involves multiple healthcare professionals with general and specific knowledge and skills. However, few interprofessional education programs exist in childhood cancer. This feasibility study assesses the acceptability, demand, practicality, and implementation of postgraduate interprofessional case-based learning for healthcare professionals from 13 different occupational groups working with children and adolescents with cancer. The study design is interventional, with subjective and objective assessment measures. Outcome measures provide sufficient information to inform a randomized controlled trial. Results from this feasibility study could be useful in the planning, design, and evaluation of postgraduate interprofessional education in other settings.

Abstract: This paper presents a feasibility study assessing the acceptability, demand, implementation, and practicality of postgraduate interprofessional case-based learning in childhood cancer at Copenhagen University Hospital-Rigshospitalet. Healthcare professionals included nurses, doctors, social workers, physiotherapists, occupational therapists, pharmacists, pharmacologists, dieticians, nursing assistants, and professionals with a supportive function (teachers, secretaries, priests, and daycare workers). All participated in a postgraduate interprofessional case-based learning session. Feasibility was assessed using Bowen's focus areas of acceptability, demand, implementation, and practicality. Before and after the intervention session, three measurement tools were used 2-3 weeks before participation and 3-4 weeks after participation to collect data: Assessment of Interprofessional Team Collaboration Scale, Readiness for Interprofessional Learning Scale, and Safety Attitudes Questionnaire. Representing 13 occupational groups, 49 participants completed the case-based learning sessions, indicating acceptability and practicality. The pre- and post-intervention questionnaires were completed by $79 \%$ of the participants, $88 \%$ of whom rated the professional content as good or very good. A change over time was detected on all three scales measuring mean difference post-intervention scores. The outcome measures can be used to assess the effect of the intervention. Postgraduate interprofessional case-based learning in childhood cancer is feasible in terms of acceptability, demand, implementation, and practicality. Implementation requires leadership commitment at all levels. 
Keywords: interprofessional; postgraduate; childhood cancer; case-based learning

\section{Introduction}

Continuing professional development seeks not only to increase the knowledge of healthcare professionals but also to improve their skills and attitudes towards providing safe and effective care [1]. In clinical practice, healthcare professionals collaborate to the best of their knowledge and skills to ensure high-quality care, without necessarily knowing the competencies, roles, and responsibilities of other team members [2,3]. However, this knowledge is a prerequisite for interprofessional collaboration seeking to optimize patient care [4].

Childhood cancer healthcare involves multiple healthcare professionals with general and specialized knowledge and skills. Ensuring and strengthening high-quality treatment and care for children and adolescents with cancer and their families requires continuous professional development and maintenance of the skills and qualifications of healthcare professionals' competencies. This includes monoprofessional and interprofessional competencies [5]. Consequently, interprofessional education must be strategically planned based on a curriculum framework comprising problem identification, needs assessment, aims and objectives, educational strategies, implementation, assessment and evaluation, and feedback [6].

Originating at Harvard Business School in 1920, case-based learning is a well-established discussion-based educational method [7]. In medical education, Thistlethwaite et al. defined case-based learning as preparing students for clinical practice through the use of authentic clinical cases, linking theory to practice using enquiry-based learning methods [8].

Medical educational interventions should be both efficient and effective in order to adhere to the gold standard of medical research. However, assessing the effects of educational interventions is complex and multifactorial. Adding to the complexity of efficacy assessment in interprofessional education is the scarcity of reliable outcome measurements $[9,10]$. However, case-based learning has been proven to have long-term clinical effects. Kiessling et al. distributed new guidelines on the management of lipid levels in patients with coronary heart disease to all general practitioners in a specific region [11,12], after which the doctors were divided into two groups: one receiving traditional lectures and one case-based learning. Notably, the group of patients whose doctors had participated in case-based learning had markedly decreased lipid levels and reduced overall mortality [12].

To identify problems and to assess the need for interprofessional education in childhood cancer, we conducted a scoping review that identified only nine articles suggesting a lack of well-structured and well-evaluated interprofessional education [13]. The review also found that none of the interventions included more than four healthcare professions and that they predominantly targeted doctors and nurses.

Subsequently, we formulated aims and objectives based on a three-round Scandinavian Delphi study [14] identifying 168 learning objectives in six categories: acute lifethreatening situations, gastrointestinal side effects, pain, palliation, play and activity, and the prescription and administration of medicine.

As the complex treatment and care of children and adolescents with cancer involves more than four healthcare professionals, we designed interprofessional case-based learning sessions for 13 occupational groups of healthcare professionals and professionals holding a supportive function. To determine the feasibility and potential implementation of postgraduate interprofessional education, the objective of this feasibility study was to test the acceptability, demand, implementation, and practicality of interprofessional case-based learning sessions in childhood cancer. 


\section{Materials and Methods}

To allow reproducibility and transparency, we employed Bowen et al.'s [15] framework for assessing feasibility. Feasibility studies are ideal for interventions in fields where few have been conducted, such as postgraduate interprofessional case-based learning studies, and can be applied to examine methodological issues that may occur in designing new interventions [15]. Bowen et al. listed eight general focus areas, some of which are relevant for particular intervention phases and depend on the outcome of interest [15]. In this feasibility study, we focus on four areas-acceptability, demand, implementation, and practicality-to assess the methodological and practical aspects of implementing postgraduate interprofessional education. Table 1 provides an overview of the focus areas, definitions, and measures applied in this feasibility study.

Table 1. Selected areas of focus for feasibility studies and possible outcomes according to Bowen et al.

\begin{tabular}{|c|c|c|}
\hline Focus Area & Definitions & Outcomes According to Bowen et al. \\
\hline Acceptability & Interest and willingness to participate & Individual satisfaction; Intend to use \\
\hline Demand & $\begin{array}{l}\text { Extent to which a new } \\
\text { intervention/program is likely to } \\
\text { be used }\end{array}$ & Fit with organizational culture; Actual use \\
\hline Implementation & $\begin{array}{l}\text { Extent to which an intervention can be } \\
\text { implemented as planned } \\
\text { and proposed }\end{array}$ & $\begin{array}{l}\text { Degree of execution; Success or failure } \\
\text { of execution }\end{array}$ \\
\hline Practicality & $\begin{array}{l}\text { Extent to which the program can be } \\
\text { carried out with intended participants } \\
\text { using the existing means, resources, } \\
\text { and circumstances }\end{array}$ & $\begin{array}{l}\text { Amount and type of resources needed to } \\
\text { implement; Factors affecting ease or } \\
\text { difficulty of implementation; Ability of } \\
\text { participants to carry out } \\
\text { intervention activities }\end{array}$ \\
\hline
\end{tabular}

The study was registered with clinicaltrials.gov, number: NCT04204109. The feasibility study complies with the General Data Protection Regulation. Relevant approval by the Danish Data Protection Agency was obtained: P-2019-637. The trial is exempt from approval by the National Committee on Health Ethics Research: H-19087506.

\subsection{Planning of the Intervention}

We planned the intervention in collaboration with the management and the scheduling coordinators at the four clinical departments. The first and last author met regularly with management to ensure recruitment and support for the case-based learning sessions [16]. The intervention was scheduled six months in advance to take place during regular working hours on a specific date. The first author met with the scheduling coordinators to organize dates and times. The healthcare professionals were randomized by computer-generated allocation sequence to participate in one case-based learning session. The randomization was designed to ensure an adequate composition of health professionals resembling authentic clinical teams of 10-18 people (e.g., four nurses, two doctors, one physiotherapist, one priest, one teacher, one social worker, and one pharmacist). Further details are available in the protocol [16].

\subsection{Details of the Intervention}

The intervention design was based on the case-based learning literature $[11,12,17]$ and the research team's didactic experience [18]. For details on the intervention, including examples of the learning objectives applied, see the protocol [16]. We conducted four interprofessional case-based learning sessions. At the core of the case method was a real patient situation based on anonymized data containing no identifiable traits. The case was open to interpretation, depending on the profession of healthcare personnel regarding the causes of problems and potential solutions. For a case example, see the protocol [16]. Tabloid-size papers mounted on the wall guided and synchronized the group's work in a structured manner [18]. This structure originates from heuristic clinical problem solving 
(definition of problems, gathering of facts, hypothesis, hypothesis testing, and feedback). Each session consisted of three and a half hours of case-based learning [16].

Two weeks to one month before the case-based learning session, the participants received an email with a link to three questionnaires (Assessment of Interprofessional Team Collaboration Scale (AITCS), Readiness for Interprofessional Learning Scale (RIPLS), and Safety Attitudes Questionnaire (SAQ)) generated in the secure web application REDCap [19]. A follow-up questionnaire was sent to the participants 4-6 weeks after the intervention, with a link to the same three questionnaires. The participants answered a multiple-choice quiz (MCQ) on the management of gastrointestinal side effects at the case-based learning session, prior to the case and immediately after.

\subsection{Inclusion and Exclusion Criteria}

All healthcare professionals employed at the four departments at Copenhagen University Hospital-Rigshospitalet were eligible to participate in the feasibility study. The four clinical departments were as follows: inpatient clinic for children and adolescents with cancer; inpatient clinic for hematopoietic stem cell transplantation of children and adolescents with cancer; and two outpatient clinics for children and adolescents with cancer. Other eligible professionals, such as social workers, physiotherapists, occupational therapists, pharmacists, pharmacologists, teachers, secretaries, priests, dieticians, nursing assistants, and daycare workers, held supportive functions (Table 2).

Table 2. Demographic data of healthcare professional groups, mean age, and mean years of paediatric experience.

\begin{tabular}{|c|c|c|c|}
\hline & Healthcare Professional Group & $\begin{array}{c}\text { Mean Age } \\
\text { (Minimum-Maximum) }\end{array}$ & $\begin{array}{c}\text { Mean Years of Pediatric Experience } \\
\text { (Minimum-Maximum) }\end{array}$ \\
\hline Case-Based Learning 1 & $\begin{array}{c}6 \text { nurses } \\
2 \text { doctors } \\
1 \text { dietician } \\
1 \text { daycare worker } \\
1 \text { secretary } \\
1 \text { pharmacist } \\
1 \text { pharmacologist } \\
1 \text { physiotherapist }\end{array}$ & $41(28-62)$ & $8(1-20)$ \\
\hline Case-Based Learning 2 & $\begin{array}{c}6 \text { nurses } \\
1 \text { doctor } \\
1 \text { occupational } \\
\text { therapist } \\
1 \text { pharmacist } \\
1 \text { physiotherapist }\end{array}$ & $33(27-42)$ & $5(2-10)$ \\
\hline Case-Based Learning 3 & $\begin{array}{c}7 \text { nurses } \\
2 \text { doctors } \\
1 \text { teacher } \\
1 \text { nurse assistant } \\
1 \text { dietician } \\
1 \text { secretary } \\
1 \text { priest } \\
1 \text { pharmacist } \\
1 \text { physiotherapist }\end{array}$ & $41(26-68)$ & $12(1-41)$ \\
\hline Case-Based Learning 4 & $\begin{array}{c}3 \text { nurses } \\
2 \text { teachers } \\
1 \text { doctor } \\
1 \text { social worker } \\
1 \text { priest } \\
1 \text { pharmacist }\end{array}$ & $44(26-67)$ & $15(2-33)$ \\
\hline Total & 49 & $39(26-68)$ & $10(1-41)$ \\
\hline
\end{tabular}

Exclusion criteria were members of staff management, leadership, and professionals with no patient contact.

\subsection{Development and Testing of Case}

An interprofessional research group consisting of four doctors and two nurses designed the case based on the learning objectives from the Delphi study [14] and on casebased learning literature $[7,17,20-23]$. Details on the development and testing of the case are presented in the study protocol $[16,18]$. The anonymized patient case was developed to 
include clinical problems relevant to all healthcare professionals. The case was pilot tested on 17 healthcare professionals, the composition of which resembled the interprofessional group allocated to the intervention [16]. We trained three facilitators, two medical doctors, and one nurse to facilitate the discussions [16,18].

\subsection{Outcome Measures}

To test healthcare professionals' knowledge of and attitudes towards collaboration and interprofessional learning, we used three online questionnaires employing a five-point Likert scale that were professionally translated and validated for a Danish context [24-27]. AITCS comprises 37 statements in three subscales: partnership and shared decision-making (19 items); cooperation (11 items); and coordination (7 items) [28]. RIPLS, which is primarily used in an undergraduate context but is also validated for healthcare professionals, has 26 items in three subscales: teamwork and collaboration (8 items); professional identity (6 items); and roles and responsibilities (12 items) [29,30]. Finally, SAQ assesses the patient safety climate and comprises 32 items [31].

\subsubsection{Development and Testing of Multiple-Choice Quiz}

A multiple-choice quiz (MCQ) consisting of a one-best-answer format was developed based on recommendations for designing and developing MCQs [32-35]. National guidelines and learning objectives on gastrointestinal side effects informed the items in the MCQ, which was tested for face and content validity [36]. The national guidelines were distributed to the participants before the case-based learning session by email and course material available online [37]. The MCQ was intended to measure the participants' knowledge of the management of gastrointestinal side effects. Figure 1 illustrates the timeline for the distribution of the questionnaires.

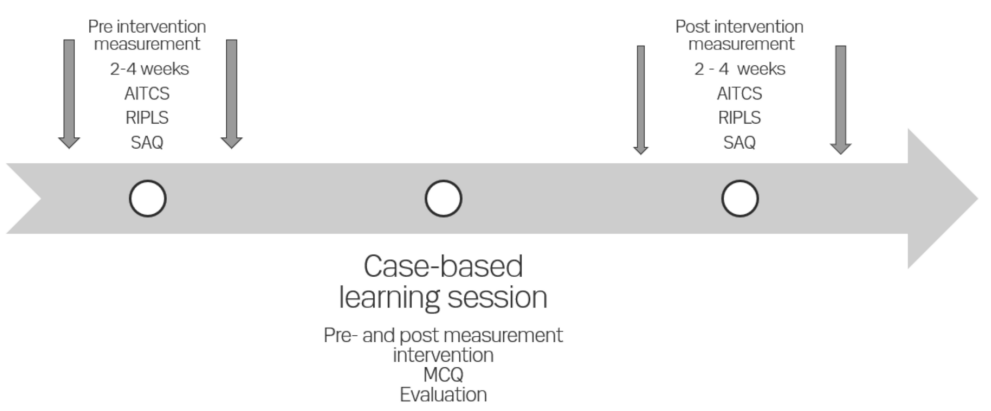

Figure 1. Timeline illustrating the distribution of questionnaires. AITCS - Assessment of Interprofessional Team Collaboration Scale. RIPLS - Readiness for Interprofessional Learning Scale. SAQ Safety and Attitude Questionnarie. MCQ - Multiple Choice Quiz.

\subsubsection{Evaluation}

At the end of the case-based learning sessions, participants rated their session based on five questions on a five-point scale: $1=$ very poor, $2=$ poor, $3=$ acceptable, $4=$ good, and $5=$ very good [16]. After each session, we evaluated what the facilitators did to activate participants $[16,18]$.

\section{Results}

Among the 59 healthcare professionals eligible to participate in the feasibility study, 49 participated (Table 2 presents the demographic data).

\subsection{Feasibility of the Intervention}

\subsubsection{Acceptability}

There was a broad interest and willingness to participate in the intervention among all 13 healthcare professional groups. In total, 59 healthcare professionals were randomized to participate. The professional content of the interprofessional case-based learning sessions 
was rated as high or very high ( $88 \%$ ); $92 \%$ found the presence of other healthcare professionals to be good or very good; and $83 \%$ would recommend or definitely recommend their presence to others (Table 3).

In the four sessions, the case varied in intensity and new questions emerged, depending on which groups of healthcare professionals were present and how the facilitator managed to invite those participants who were not explicitly mentioned in the case to speak. During the case-based learning sessions, we found that it was paramount to explicitly invite participants from professions other than nurses and doctors to share their professional view and contribute with questions and reflections-both on their own and other professionals' practice [18].

Table 3. Feasibility results based on Bowen et al.'s focus areas.

\begin{tabular}{|c|c|c|}
\hline Focus Area & Definitions & Outcomes in Feasibility Study \\
\hline Acceptability & Interest and willingness to participate in study & $\begin{array}{l}13 \text { healthcare professional groups ( } 59 \text { healthcare } \\
\text { professionals in total) were randomized to participate } \\
\text { in the study } \\
44 \% \text { rated the professional content to be high and } \\
44 \% \text { rated it to be very high } \\
40 \% \text { found the presence of other healthcare } \\
\text { professionals to be good and } \\
52 \% \text { found the presence of other healthcare } \\
\text { professionals to be very good } \\
27 \% \text { would recommend and } 56 \% \text { would definitely } \\
\text { recommend the presence of other healthcare } \\
\text { professionals to others }\end{array}$ \\
\hline Demand & $\begin{array}{l}\text { Extent to which a new intervention/program is } \\
\text { likely to be used }\end{array}$ & $\begin{array}{l}\text { Interprofessional education is a particular focus area } \\
\text { in hospital strategy }\end{array}$ \\
\hline Implementation & $\begin{array}{l}\text { Extent to which an intervention can be } \\
\text { implemented as planned and proposed }\end{array}$ & $\begin{array}{l}49 \text { out of } 59 \text { healthcare professionals participated, } \\
\text { representing } 13 \text { healthcare professional groups }\end{array}$ \\
\hline Practicality & $\begin{array}{l}\text { Extent to which the program can be carried out } \\
\text { with intended participants using the existing } \\
\text { means, resources, and circumstances }\end{array}$ & $\begin{array}{l}13 \text { healthcare professional groups were able to } \\
\text { participate in the allotted time } \\
79 \% \text { answered pre- and post-intervention } \\
\text { questionnaires (AICTS, RIPLS, SAQ) } \\
17 \% \text { dropped out }\end{array}$ \\
\hline
\end{tabular}

AITCS, Assessment of Interprofessional Team Collaboration Scale; RIPLS, Readiness for Interprofessional Learning Scale; SAQ, Safety and Attitudes Questionnaire.

\subsubsection{Demand}

The foundation for the feasibility study was based on the hospital management strategy that patient satisfaction relies on research and education [37]. As interprofessional education is a particular focus area in the hospital strategy to build bridges between healthcare professionals in different wards, the intervention was suitable in terms of the organizational structure.

\subsubsection{Implementation}

Leaders of healthcare professionals and professionals from supportive functions from four departments were approached for recruitment. They supported the participation of their employees, and a total of 49 healthcare professionals participated in one of the four case-based learning sessions, indicating that the intervention could be implemented as planned. It was possible to use the applied outcome measures to assess the effect of the intervention. The mean scores changed over time for the participants on all three measurement tools assessing the attitudes of the healthcare professionals towards interprofessional learning and collaboration (AITCS, RIPLS, and SAQ). The improvement in both AITCS ( $p=0.02)$ and RIPLS $(p=0.048)$ was significant (Table 4). For the MCQ, the mean scores increased for the participants $(p=0.07)$. The MCQ was designed to be of relevance 
to all healthcare professionals working with children and adolescents with cancer, but some groups had difficulty answering the quiz compared to nurses and doctors, which is reflected in the number of unanswered questions. Unanswered questions were calculated as incorrect.

Table 4. All data are presented as estimated means and 95\% confidence intervals (CIs).

\begin{tabular}{ccccc}
\hline & Pre-Intervention & Post-Intervention & Change over Time 95\% CI $^{p_{\text {-Value }}}$ \\
\hline AITCS $^{2}$ & $141.8(135.5-148.0)$ & $147.7(141.1-154.3)$ & $5.9(1.1-10.7)$ & 0.02 \\
RIPLS $^{3}$ & $109.0(106.2-112.0)$ & $112.0(109.0-115.1)$ & $2.8(-0.06-5.8)$ & 0.048 \\
SAQ $^{4}$ & $125.0(122-128.2)$ & $124.3(121-128)$ & $-0.7(-3.7-2.3)$ & 0.64 \\
MCQ $^{5}$ & $14.3(12.7-15.7)$ & $15.0(13.5-16.5)$ & $0.8(-0.08-1.7)$ & 0.07 \\
\hline
\end{tabular}

${ }^{1}$ Linear mixed model with time as a fixed effect, and team and individual as random effects. ${ }^{2}$ AITCS, Assessment of Interprofessional Team Collaboration Scale. ${ }^{3}$ RIPLS, Readiness for Interprofessional Learning Scale. ${ }^{4}$ SAQ, Safety and Attitudes Questionnaire. ${ }^{5} \mathrm{MCQ}$, multiple-choice quiz.

\subsubsection{Practicality}

The case-based learning sessions were planned to take place twice a day, as requested by the management and scheduling coordinators. Coordinating the group of nurses was uncomplicated as the leaders of the departments had approved the intervention, just as any holidays, leave, or other courses were taken into account. Coordinating the group of medical doctors was more complex. First, the doctors refer to individual schedule planners, who are themselves medical doctors working in the clinic. Second, while nurses cover three shifts a day, medical doctors do 12 hour shifts. During allocation of staff to the specific casebased learning six months before the start of the intervention, new healthcare professionals were hired. Staff turnover, especially for doctors and nurses, was high: $17.9 \%$ and $26.6 \%$, respectively (Data from Centre for Financial Affairs, Capital Region of Denmark).

All 49 participants completed the evaluation forms at the end of each session. Even though some healthcare professionals found the questionnaires complex and time-consuming, the response rates of the pre- and post-intervention questionnaires were high (79\%). In the four sessions, the case varied in intensity and new questions emerged, depending on which groups of healthcare professionals were present and how the facilitator managed to invite those participants who were not explicitly mentioned in the case to speak. There was markedly more absence in the afternoon sessions (39\% and $31 \%$ in the afternoon versus $13 \%$ and $6 \%$ in the morning), indicating that abandoning clinical activities can be difficult in the middle of the day (Table 3).

\section{Discussion}

This feasibility study demonstrates that postgraduate interprofessional case-based learning is feasible and acceptable. Applying the three measurement tools prior to and after the case-based learning sessions was accepted, and the high levels of participation suggest that implementation of the intervention is possible. The use of time and resources, and a commitment from management at the clinical departments, demonstrated that the practical aspects of the intervention were acceptable (see Figure 2).

The outcome measures suggest that interprofessional case-based learning can potentially influence healthcare professionals' knowledge of and attitudes towards collaboration and interprofessional learning. In line with previous research on case-based learning [8], participants were very satisfied and would recommend participating in interprofessional case-based learning to others. The implications of this study for practice include the integration of clinically relevant topics into postgraduate interprofessional education. 


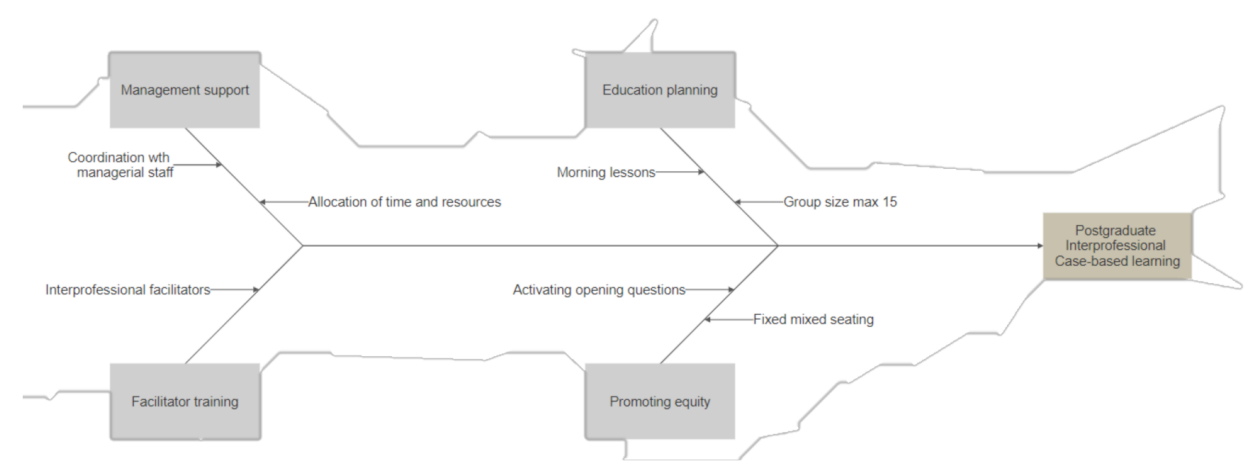

Figure 2. Summarizing flowchart of practical aspects for postgraduate interprofessional case-based learning.

Facilitating case-based learning requires experience with enquiry-based teaching, including how to engage various types of learners and diverse healthcare professionals with various levels of education, work experience, and roles and responsibilities in discussions $[18,38]$. Opening with questions that activate all healthcare professionals can be used to reduce traditional hierarchical structures [18,20]. Consequently, the facilitator must take responsibility for promoting equity between the groups of healthcare professionals so that all voices and professions are represented $[18,39,40]$. To allow sufficient time for all participants, we suggest that group sizes should not exceed 15 to provide space for all professional groups to speak [18]. Educational activities should also take place in the morning due to the higher degree of cancellations for afternoon sessions. Morning sessions appear to be better suited to the organizational activities and clinical workflow.

Participating in everyday work activities is considered a highly common learning model [3]. Noe et al. stipulated that $70 \%$ of learning occurs day to day at the workplace, $20 \%$ through social relations and mentors, and 10\% through formal education, courses, and certification [41]. However, learning at work is no guarantee for effective learning, and leadership buy-in is imperative for the success of educational interventions [42]. Previous interprofessional educational interventions have successfully recruited doctors, midwives, and nurses with high levels of completion [43]. The planning and execution of postgraduate educational programs require coordination with managerial staff and leadership. Educational initiatives should be an integral part of the organizations' policies, strategies, and practices $[41,44,45]$ as coordinating between 13 groups of healthcare professionals, their separate leaders, and their work routines can be complicated.

The planning of the 13 groups of healthcare professionals was challenging, as staff turnover-especially among doctors and nurses-was high. Any new employees had to be informed about the intervention and added to the existing randomization. This aspect also required a commitment from leadership at all levels to prioritize interprofessional education as part of the existing introductory program. Existing educational programs, such as specialization courses for medical doctors and recurring international conferences, had to be considered in the planning. This highlights that human resource issues and logistical challenges require designated resources embedded in the organization $[20,40,46]$.

\section{Conclusions}

In conclusion, postgraduate interprofessional case-based learning is feasible, and outcome measures provide sufficient information to inform a randomized controlled trial. Results from this feasibility study may be useful in the planning, design, and evaluation of postgraduate interprofessional education in other settings. The organization and implementation of postgraduate interprofessional education require interprofessional planning and implementation, as well as a clear commitment from leadership to ensure acceptability, demand, practicality, and implementation. 
Author Contributions: M.K.T., H.B.L., M.H., K.S. and J.L.S. formulated the objective of the originally planned RCT; M.K.T., L.I.R., L.A.-J., P.E.L.P., M.H. and J.L.S. developed, tested, and carried out the case-based learning sessions; M.K.T., M.H., H.B.L. and J.L.S. developed the MCQ; M.K.T., M.K.F. and S.R. performed the statistical analysis; M.K.T. wrote the first draft of the manuscript. All authors have read and agreed to the published version of the manuscript.

Funding: This research was funded by the Danish Childhood Cancer Foundation grant number: 2015-73.

Institutional Review Board Statement: The study, conducted according to the guidelines of the Declaration of Helsinki, is registered with clinicaltrials.gov, number: NCT04204109. The feasibility study complies with the General Data Protection Regulation. Relevant approval by the Danish Data Protection Agency was obtained: P-2019-637. The trial is exempt from approval by the National Committee on Health Ethics Research: H-19087506.

Informed Consent Statement: Informed consent was obtained from all subjects involved in the study.

Data Availability Statement: The data presented in this study are available on request from the corresponding author. The data are not publicly available due to privacy.

Acknowledgments: We wish to thank the head of clinical services, Karen Vitting Andersen; head of department Lisa Hjalgrim; and head nurses Marianne Madsen and Pernille Roland for making this intervention possible. We would also like to thank managers Maria Bennedsen, Karen Berget, Lone Stisen, and Lone Sparrevohn Mørck for prioritizing the participation of their healthcare professional employees in this feasibility study.

Conflicts of Interest: The authors declare no conflict of interest. The funders had no role in the design of the study; in the collection, analysis, or interpretation of data; in the writing of the manuscript; or in the decision to publish the results.

\section{References}

1. Allen, L.M.; Palermo, C.; Armstrong, E.; Hay, M. Categorising the broad impacts of continuing professional development: A scoping review. Med. Educ. 2019, 53, 1087-1099. [CrossRef] [PubMed]

2. Thistlethwaite, J. Interprofessional education: A review of context, learning and the research agenda. Med. Educ. 2011, 46, 58-70. [CrossRef] [PubMed]

3. Billett, S. Learning through health care work: Premises, contributions and practices. Med. Educ. 2015, 50, 124-131. [CrossRef]

4. D'Amour, D.; Oandasan, I. Interprofessionality as the field of interprofessional practice and interprofessional education: An emerging concept. J. Interprof. Care 2005, 19, 8-20. [CrossRef] [PubMed]

5. Anderson, R.A.; Marshall, N.S. The importance of the pediatric oncologist-nurse partnership in the delivery of total care in pediatric oncology. Med. Pediatr. Oncol. 2000, 34, 263-264. [CrossRef]

6. Thomas, P.A.; Kern, D.E.; Hughes, M.T.; Chen, B.Y. Curriculum Development for Medical Education: A Six-Step Approach; Springer: Baltimore, MD, USA, 2016.

7. H.B. School. Case-Based Learning. Available online: https://www.hbs.edu/mba/academic-experience/Pages/the-hbs-casemethod.aspx (accessed on 6 August 2020).

8. Thistlethwaite, J.E.; Davies, D.; Ekeocha, S.; Kidd, J.M.; MacDougall, C.; Matthews, P.; Purkis, J.; Clay, D. The effectiveness of case-based learning in health professional education. A BEME systematic review: BEME Guide No. 23. Med. Teach. 2012, 34, e421-e444. [CrossRef]

9. Reeves, S.; Pelone, F.; Harrison, R.; Goldman, J.; Zwarenstein, M. Interprofessional collaboration to improve professional prac-tice and healthcare outcomes. Cochrane Database Syst. Rev. 2017, 6, Cd000072. [PubMed]

10. Reeves, S.; Perrier, L.; Goldman, J.; Freeth, D.; Zwarenstein, M. Interprofessional education: Effects on professional practice and healthcare outcomes (update). Cochrane Database Syst. Rev. 2013, 3, Cd002213. [CrossRef]

11. Kiessling, A.; Henriksson, P. Efficacy of case method learning in general practice for secondary prevention in patients with coronary artery disease: Randomised controlled study. BMJ 2002, 325, 877-880. [CrossRef]

12. Kiessling, A.; LeWitt, M.; Henriksson, P. Case-Based Training of Evidence-Based Clinical Practice in Primary Care and Decreased Mortality in Patients With Coronary Heart Disease. Ann. Fam. Med. 2011, 9, 211-218. [CrossRef]

13. Topperzer, M.K.; Hoffmann, M.; Roug, L.I.; Larsen, H.B.; Lausen, B.; Schmiegelow, K.; Sørensen, J.L. Unmet need for interprofessional education in paediatric cancer: A scoping review. Supportive Care Cancer 2019, 27, 3627-3637. [CrossRef]

14. Topperzer, M.K.; Thellesen, L.; Hoffmann, M.; Larsen, H.B.; Weibel, M.; Lausen, B.; Schmiegelow, K.; Sørensen, J.L. Establishment of consensus on content and learning objectives for an interprofessional education in childhood cancer: A Delphi survey. BMJ Paediatr. Open 2020, 4, e000634. [CrossRef] [PubMed]

15. Bowen, D.J.; Kreuter, M.; Spring, B.; Cofta-Woerpel, L.; Linnan, L.; Weiner, D.; Bakken, S.; Kaplan, C.P.; Squiers, L.; Fabrizio, C.; et al. How We Design Feasibility Studies. Am. J. Prev. Med. 2009, 36, 452-457. [CrossRef] [PubMed] 
16. Topperzer, M.K.; Hoffmann, M.; Larsen, H.B.; Rosthøj, S.; Nersting, J.; Roug, L.I.; Pontoppidan, P.; Andrés-Jensen, L.; Lausen, B.; Schmiegelow, K.; et al. Interprofessional versus monoprofessional case-based learning in childhood cancer and the effect on healthcare professionals' knowledge and attitudes: Study protocol for a randomised trial. BMC Health Serv. Res. 2020, 20, 1124. [CrossRef]

17. Lindqvist, S.; Duncan, A.; Shepstone, L.; Watts, F.; Pearce, S. Case-based learning in cross-professional groups-the develop-ment of a pre-registration interprofessional learning programme. J. Interprof. Care 2005, 19, 509-520. [CrossRef] [PubMed]

18. Topperzer, M.K.; Roug, L.I.; Andrés-Jensen, L.; Pontoppidan, P.; Hoffmann, M.; Larsen, H.B.; Schmiegelow, K.; Sørensen, J.L. Twelve tips for postgraduate interprofessional case-based learning. Med. Teach. 2021, 1-14. [CrossRef] [PubMed]

19. Harris, P.A.; Taylor, R.; Thielke, R.; Payne, J.; Gonzalez, N.; Conde, J.G. Research electronic data capture (REDCap)—A metada-tadriven methodology and workflow process for providing translational research informatics support. J. Biomed. Inform. 2009, 42, 377-381. [CrossRef]

20. O’Brien, B.C.; Patel, S.R.; Pearson, M.; Eastburn, A.P.; Earnest, G.E.; Strewler, A.; Gager, K.; Manuel, J.K.; Dulay, M.; Bachhuber, M.R.; et al. Twelve tips for delivering successful interprofessional case conferences. Med. Teach. 2017, 39, 1214-1220. [CrossRef]

21. Tärnvik, A. Revival of the case method: A way to retain student-centred learning in a post-PBL era. Med. Teach. 2007, 29, e32-e36. [CrossRef]

22. Tärnvik, A. Advantages of using the multiple case method at the clinical stage of medical education. Med. Teach. 2002, 24, 396-401. [CrossRef]

23. Siassakos, D.; Crofts, J.F.; Winter, C.; Weiner, C.P.; Draycott, T.J. The active components of effective training in obstetric emergencies. BJOG 2009, 116, 1028-1032. [CrossRef] [PubMed]

24. Marcussen, M.; Nørgaard, B.; Borgnakke, K.; Arnfred, S. Interprofessional clinical training in mental health improves students' readiness for interprofessional collaboration: A non-randomized intervention study. BMC Med. Educ. 2019, 19, 27. [CrossRef]

25. Hellman, T.; Jensen, I.; Orchard, C.; Bergström, G. Preliminary testing of the Swedish version of the Assessment of Interprofessional Team Collaboration Scale (AITCS-S). J. Interprof. Care 2016, 30, 499-504. [CrossRef] [PubMed]

26. Kristensen, S.; Sabroe, S.; Bartels, P.; Mainz, J.; Christensen, K.B. Adaption and validation of the Safety Attitudes Questionnaire for the Danish hospital setting. Clin. Epidemiol. 2015, 7, 149-160. [CrossRef] [PubMed]

27. Nørgaard, B.; Draborg, E.; Sørensen, J. Adaptation and reliability of the Readiness for Inter professional Learning Scale in a Danish student and health professional setting. BMC Med. Educ. 2016, 16, 60. [CrossRef]

28. Orchard, C.A.; King, G.A.; Khalili, H.; Bezzina, M.B. Assessment of Interprofessional Team Collaboration Scale (AITCS): De-velopment and testing of the instrument. J. Contin. Educ. Health Prof. 2012, 32, 58-67. [CrossRef]

29. Reid, R.; Bruce, D.; Allstaff, K.; McLernon, D. Validating the Readiness for Interprofessional Learning Scale (RIPLS) in the postgraduate context: Are health care professionals ready for IPL? Med. Educ. 2006, 40, 415-422. [CrossRef]

30. McFadyen, A.K.; Webster, V.; Strachan, K.; Figgins, E.; Brown, H.; Mckechnie, J. The Readiness for interprofessional learning scale: A possible more stable sub-scale model for the original version of RIPLS. J. Interprof. Care 2005, 19, 595-603. [CrossRef]

31. Sexton, J.B.; Helmreich, R.L.; Neilands, T.B.; Rowan, K.; Vella, K.; Boyden, J.; Roberts, P.R.; Thomas, E.J. The Safety Attitudes Questionnaire: Psychometric properties, benchmarking data, and emerging research. BMC Health Serv. Res. 2006, 6, 44. [CrossRef]

32. Sørensen, J.L.; Thellesen, L.; Strandbygaard, J.; Svendsen, K.D.; Christensen, K.B.; Johansen, M.; Langhoff-Roos, P.; Ekelund, K.; Ottesen, B.; Van Der Vleuten, C. Development of knowledge tests for multi-disciplinary emergency training: A review and an example. Acta Anaesthesiol. Scand. 2014, 59, 123-133. [CrossRef] [PubMed]

33. Schurmirth, L.; van der Vleuten, C. ABC of learning and teaching in medicine: Written assessment. BMJ 2003, 326, 643-645. [CrossRef]

34. Burford, B.; Hesketh, A.; Wakeling, J.; Bagnall, G.; Colthart, I.; Illing, J.; Kergon, C.; Morrow, G.; Spencer, J.; Van Zwanenberg, T. Asking the right questions and getting meaningful responses: 12 tips on developing and administering a questionnaire survey for healthcare professionals. Med. Teach. 2009, 31, 207-211. [CrossRef] [PubMed]

35. Fayers, P. Developing a Questionnaire. Qual. Life 2007, 49-76.

36. Topperzer, M.K. Available online: https://www.rigshospitalet.dk/afdelinger-og-klinikker/julianemarie/enhed-for-simulation/ for-fagfolk/simulationsbaseret-forskning-og-traening/Sider/incase-interprofessional-cancer-education.aspx (accessed on 5 May 2020)

37. Centret, J.M. Strategi 2020-deter resultatet for patienten der tæller. Available online: https://publikationer.regionh.dk/pdf/full5648/strategi-2020.pdf (accessed on 5 May 2020).

38. Freeman, S.; Wright, A.; Lindqvist, S. Facilitator training for educators involved in interprofessional learning. J. Interprofessional Care 2010, 24, 375-385. [CrossRef] [PubMed]

39. Hammick, M.; Freeth, D.; Koppel, I.; Reeves, S.; Barr, H. A best evidence systematic review of interprofessional education: BEME Guide no. 9. Med. Teach. 2007, 29, 735-751. [CrossRef] [PubMed]

40. Boet, S.; Bould, M.D.; Layat Burn, C.; Reeves, S. Twelve tips for a successful interprofessional team-based high-fidelity simula-tion education session. Med. Teach. 2014, 36, 853-857. [CrossRef] [PubMed]

41. Noe, R.; Clarke, A.D.; Klein, H.J. Learning in the Twenty-First-Century Workplace. Annu. Rev. Organ. Psychol. Organ. Behav. 2014, 1, 245-275. [CrossRef] 
42. Sunguya, B.F.; Hinthong, W.; Jimba, M.; Yasuoka, J. Interprofessional Education for Whom?-Challenges and Lessons Learned from Its Implementation in Developed Countries and Their Application to Developing Countries: A Systematic Review. PLOS ONE 2014, 9, e96724. [CrossRef]

43. Sørensen, J.L.; Van Der Vleuten, C.; Rosthøj, S.; Østergaard, D.; Leblanc, V.; Johansen, M.; Ekelund, K.; Starkopf, L.; Lindschou, J.; Gluud, C.; et al. Simulation-based multiprofessional obstetric anaesthesia training conducted in situ versus off-site leads to similar individual and team outcomes: A randomised educational trial. BMJ Open 2015, 5, e008344. [CrossRef]

44. Ferguson, J.; Astbury, J.; Willis, S.; Silverthorne, J.; Schafheutle, E. Implementing, embedding and sustaining simulation-based education: What helps, what hinders. Med. Educ. 2020, 54, 915-924. [CrossRef]

45. Keith, R.E.; Crosson, J.C.; O'Malley, A.S.; Cromp, D.; Taylor, E.F. Using the Consolidated Framework for Implementation Re-search (CFIR) to produce actionable findings: A rapid-cycle evaluation approach to improving implementation. Implement. Sci. 2017, 12, 15. [CrossRef] [PubMed]

46. Kitto, S.; Nordquist, J.; Peller, J.; Grant, R.; Reeves, S. The disconnections between space, place and learning in interprofessional education: An overview of key issues. J. Interprof. Care 2013, 27, 5-8. [CrossRef] [PubMed] 